JURNAL Midwifery Update (MU)

http://jurnalmu.poltekkes-mataram.ac.id/index.php/jurnalmu

e-ISSN: 2684-8511 (Online)

\title{
PENGARUH SIKAP DAN PERILAKU BIDAN TERHADAP PENGETAHUAN IBU HAMIL SAAT PELAKSANAAN ANC DI WILAYAH KERJA PUSKESMAS KURIPAN
}

\author{
Anastasya Agustiarini ${ }^{1}$, Lina Sundayani ${ }^{2}$ \\ ${ }^{1}$ Jurusan Kebidanan Poltekkes Kemenkes Mataram \\ ${ }^{2}$ Jurusan Kebidanan Poltekkes Kemenkes Mataram
}

\begin{abstract}
Abstrak
Pelayanan pemeriksaan kehamilan yang sesuai, secara kuantitas dan kualitas diharapkan dapat tercapai tujuan menurunkan angka kematian ibu dengan mendekatkan fasilitas pelayanan ke masyarakat. Kenyataan yang terjadi kunjungan pemeriksaan kehamilan (K4) belum mencapai target, bahkan terjadi penurunan target dari K1.Tujuan dari penelitian ini untuk mengetahui pengaruh sikap dan prilaku bidan terhadap pengetahuan ibu hamil saat pelaksanaan ANC. Metode Penelitian ini adalah penelitian observasional dengan pendekatan analitik dengan pengumpulan data menggunakan kuesioner yang dilaksanakan pada bulan april-mei 2019. Populasi penelitian adalah ibu hamil multigravida di wilayah kerja Puskesmas Kuripan dengan sampel $30 \mathrm{ibu}$ hamil. Analisa data yang digunakan yaitu Regression Binary Logistic. Hasil Penelitian ini : Sikap bidan pada saat pelaksanaan ANC yang positif sebesar $87 \%$ Sedangkan perilaku bidan positif sebesar $77 \%$. Berdasarkan indikator tingkat pengetahuan, menunjukkan ibu yang memliki pengetahuan baik sebesar 87\%. Dari hasil uji statistik Regression Binary Logistic, nilai pvalue 0,00 nilai sig $<0,05$ tolak Ho dan Ha diterima. Kesimpulan : Terdapat pengaruh sikap dan perilaku bidan terhadap tingkat pengetahuan ibu hamil saat pemeriksaan ANC di wilayah kerja Puskesmas Kuripan tahun 2019.
\end{abstract}

Kata Kunci : Sikap ; Perilaku ; Bidan ; Pengetahuan

\section{THE INFLUENCE OF MIDWIVE'S ATTITUDES AND BEHAVIOR ON THE KNOWLEDGE OF PPREGNANT WOMEN IN THE WORKING AREA OF KURIPAN HEALTH CENTER}

\begin{abstract}
Proper antenatal care services, in quantity and quality, are expected to achieve the goal of reducing maternal mortality by bringing services to the community closer. The fact that a pregnancy check-up visit (K4) has not reached the target, even the target of K1 has decreased. Research objectives To find out the influence of midwives' attitudes and behavior on the knowledge of pregnant women during ANC implementation. Research Methods this study was an observational study with an analytical approach by collecting data using a questionnaire conducted in April-May 2019. The study population was multigravida pregnant women in the working area of the Kuripan Health Center with a sample of 30 pregnant women. Data analysis used is Binary Logistic Regression. Research results attitudes of midwives at the time of positive ANC implementation were $87 \%$ while positive midwives' behavior was $77 \%$. Based on the level of knowledge indicators, mothers who have good
\end{abstract}


knowledge are $87 \%$. From the results of the Binary Logistic Regression test, the value of 0.00 value sig $<0.05$ rejects Ho and $\mathrm{Ha}$ is accepted. Conclusion there are influences of attitudes and behavior of midwives on the level of knowledge of pregnant women during ANC examination in the working area of the Kuripan Health Center in 2019.

Keywords: Attitudes ; Behavior ; Midwives ; Knowledge

\section{Pendahuluan}

Pelayanan kesehatan yang diberikan oleh puskesmas merupakan pelayanan publik. Dengan pelayanan pemeriksaan kehamilan yang sesuai, secara kuantitas dan kualitas diharapkan dapat tercapai tujuan untuk memantau kemajuan kehamilan dengan memastikan kesehatan ibu dan bayi, mengetahui secara dini adanya ketidaknormalan atau komplikasi selama kehamilan, mempersiapkan persalinan di puskesmas, melahirkan bayi dengan selamat, pemberian ASI ekslusif, mempersiapkan peran ibu dan keluarga, dalam menerima kelahiran bayi agar dapat tumbuh kembang secara normal dan wajar. ${ }^{12}$

Pelayanan yang berkualitas diperlukan adanya standar pelayanan agar petugas dapat mengetahui kinerja apa yang diharapkan, apa yang dilakukan disetiap tingkat pelayanan, serta kompetensi apa yang diharapkan sehingga akan meningkatkan kualitas pelayanan yang diberikan Berdasarkan hasil studi pendahuluan cakupan pelayanan K1 dan K4 di Dinas Kesehatan Provinsi NTB, rekapitulasi pemantauan wilayah setempat kesehatan ibu dan anak (PWS KIA) tahun 2017, untuk cakupan pelayanan K1 mencapai 102,8\% sedangkan K4 mencapai 94,30\%. Untuk wilayah Kabupaten Lombok Barat, rekapitulasi pemantauan wilayah setempat kesehatan ibu dan anak (PWS KIA) bulan desember tahun 2018, untuk cakupan pelayanan K1 mencapai 102,6\% sedangkan K4 mencapai 94,74\%. ${ }^{3}$

Di Puskesmas Kuripan, menurut PWS tahun 2018 terdapat 996 ibu hamil, dimana merupakan puskesmas dengan jumlah ibu hamil terbanyak, untuk cakupan pelayanan $\mathrm{K} 1$ mencapai 101,51\% sedangkan K4 mencapai 86,83\%. (Sumber: Lap. PWS ibu tahun 2018).

Salah satu upaya pemerintah untuk menurunkan angka kematian ibu dengan mendekatkan fasilitas pelayanan ke masyarakat. Kenyataan yang terjadi kunjungan pemeriksaan kehamilan (K4) belum mencapai target, bahkan terjadi penurunan target dari K1. Sehingga berdasarkan uraian latar belakang tersebut, peneliti tertarik untuk melakukan penelitian dengan judul "Pengaruh sikap dan perilaku bidan terhadap pengetahuan ibu hamil saat pelaksanaan ANC di wilayah kerja Puskesmas Kuripan tahun 2019”

\section{Metode}

Penelitian ini adalah penelitian observasional dengan pendekatan analitik dengan pengumpulan data menggunakan kuesioner yang dilaksanakan pada bulan april- mei 2019 . Populasi penelitian adalah ibu hamil multigravida di wilayah kerja Puskesmas Kuripan dengan sampel $30 \mathrm{ibu}$ hamil. Analisa data yang digunakan yaitu Regression Binary Logisti. 


\section{Hasil dan Pembahasan}

1. Sikap Bidan saat pelaksanaan ANC

Tabel 1 Distribusi frekuensi sikap bidan saat pelaksanaan ANC di wilayah kerja Puskesmas Kuripan tahun 2019

\begin{tabular}{llcc}
\hline No & Sikap Bidan & N & $\%$ \\
\hline 1 & Positif & 26 & 87 \\
\hline 2 & Negatif & 4 & 13 \\
\hline & Jumlah & 30 & 100 \\
\hline
\end{tabular}

Berdasarkan tabel 1. tampak bahwa menurut tiap ibu hamil sikap bidan pada saat pelaksanaan ANC yang sikap positif berjumlah sebesar 87\%, dan sikap negatif sebesar $13 \%$.

2. Perilaku Bidan saat pelaksanaan ANC

Tabel 2 Distribusi frekuensi Perilaku bidan saat pelaksanaan ANC di wilayah kerja Puskesmas Kuripan tahun 2019

\begin{tabular}{clll}
\hline No & Perilaku Bidan & N & $\%$ \\
\hline 1 & Positif & 23 & 77 \\
\hline 2 & Negatif & 7 & 23 \\
\hline & Jumlah & 30 & 100
\end{tabular}

Berdasarkan tabel 2. tampak bahwa menurut ibu hamil perilaku bidan pada saat pelaksanaan ANC yang perilaku positif berjumlah sebesar $77 \%$, dan perilaku negatif sebesar $23 \%$ pengetahuan ibu hamil tentang pemeriksaan ANC.

Tabel 3 Distribusi frekuensi tingkat pengetahuan ibu hamil tentang pemeriksaan ANC di wilayah kerja Puskesmas Kuripan tahun 2019

\begin{tabular}{llcc}
\hline No & \multicolumn{1}{c}{ Pengetahuan Ibu Hamil } & $\mathrm{n}$ & $\%$ \\
\hline 1 & Baik & 26 & 87 \\
\hline 2 & Cukup & 4 & 13 \\
\hline 3 & Kurang & 0 & 0 \\
\hline & Jumlah & 30 & 100 \\
\hline
\end{tabular}

Berdasarkan tabel 4.3 tingkat pengetahuan ibu hamil yang masuk pada kategori pengetahuan baik yaitu sebesar $87 \%$, cukup $13 \%$.

3. Analisa Sikap dan Perilaku Bidan terhadap pengetahuan ibu hamil saat Pelaksanaan ANC

Dalam uji hipotesis dengan menggunakan regresi logistik biner untuk mencari adakah pengaruh sikap dan perilaku bidan terhadap pengetahuan ibu hamil saat pemeriksan ANC dapat melihat tabel omnimbus test, pada kolom signifikansi terdapat 
nilai signifikasi 0,00 menghasilkan nilai signifikasi yang lebih rendah dari 0,05 hal ini menunjukkan bahwa terdapat pengaruh yang signifikansi secara simultan atau terjadi secara bersamaan. Maka, terdapat pengaruh sikap dan perilaku bidan terhadap pengetahuan ibu hamil saat pemeriksaan ANC. Kemudian nilai nagelkerke R Square merupakan nilai yang menjelaskan seberapa besar variabel independen mempengaruhi dependen. Variabel independen mampu menjelaskan 62\% variabel dependent dan 38\% lainnya dapat dijelaskan oleh faktor lainnya diluar variabel independen dalam persamaan hasil regresi logistik.

Berdasarkan hasil pengolahan data maka dapat dinyatakan bahwa, estimasi binary logistic regression memiliki tingkat signifikan sebesar 0.00 . Kriteria uji hipotesis maka di dapatkan hasil Ho ditolak dan Ha diterima, artinya bahwa variabel sikap dan perilaku bidan berpengaruh terhadap pengetahuan ibu hamil saat pemeriksaan ANC.

Berdasarkan hasil penelitian di atas, maka peneliti akan membahas sesuai dengan tujuan peneliti adalah sebagai berikut:

1 Mengidentifikasi Sikap Bidan saat Pelaksanaan ANC

Berdasarkan hasil penelitian yang diperoleh, sikap bidan pada saat pelaksanaan ANC sebagian besar memiliki sikap positif sebesar 26 (87\%) ibu hamil, dan sikap negatif sebesar $4(13 \%)$ ibu hamil. Sikap bidan yang positif terhadap pemeriksaan kehamilan dapat dipengaruhi oleh pengetahuan ibu hamil yang baik, karena didapat bahwa sebagian besar pengetahuan ibu hamil baik. Sehingga dengan pengetahuan yang baik, ibu hamil dapat mengganggap pemeriksan kehamilan yang dilakukan bidan sangat penting. Sikap negatif juga dapat dipengaruhi oleh pengetahuan ibu hamil yang berpendidikan dasar. Sehingga dengan kurangnya pengetahuan, ibu hamil menganggap pemeriksaan yang dilakukan bidan tidak penting.

Menurut penelitian, sikap dapat diperoleh dari pengalaman sendiri atau pengalaman orang lain, kebudayaan, media massa, institusi pendidikan dan agama. Setiap hal tersebut dapat mempengaruhi bagaimana seseorang bersikap terhadap orang lain. ${ }^{12}$

Penelitian ini sejalan dengan hasil penelitian yang dilakukan Marpua tahun 2017 tentang hubungan pengetahuan dan sikap bidan dengan pelaksanaan ANC 10T di wilayah kerja puskesmas Lambuya. Didapatkan hasil dari 32 responden, sikap positif berjumlah 22 (69\%) dan sikap negatif berjumlah 10 (31\%).

Menurut peneliti sikap bidan dalam pemeriksaan ANC menurut sebagian repsonden bersikap positif. Hal ini disebabkan karena bidan memiliki pengalaman yang menyenangkan dalam pemeriksaan ANC.

2 Mengidentifikasi Perilaku Bidan saat Pelaksanaan ANC

Berdasarkan hasil penelitian yang diperoleh, perilaku bidan pada saat pelaksanaan ANC yang perilaku positif berjumlah sebesar 23 (77\%) ibu hamil, dan perilaku negatif sebesar 7 (23\%) ibu hamil. Perilaku bidan yang positif pada saat pemeriksaan kehamilan sebesar $77 \%$, artinya sebagian besar ibu hamil menganggap perilaku bidan positif atau baik saat pemeriksaan kehamilan. Sedangkan perilaku bidan 
yang negatif sebesar $7 \%$, artinya masih ada ibu hamil yang menganggap bidan saat melakukan pemeriksaan kehamilan berprilaku baik atau tidak baik. ${ }^{7}$

Penelitian ini sejalan dengan hasil penelitian yang dilakukan Komariyah tahun 2018 di mojokorto Kediri tentang hubungan pengetahuan, sikap dan perilaku ibu hamil tentang pemeriksaan kehamiilan dengan kunjungan pemeriksan kehamilan, didapatkan hasil dari 45 responden yang memiliki sikap positif berjumlah $(55 \%)$. Yang memiliki sikap negatif berjumlah 20 responden $(45 \%){ }^{7}$

Berdasarkan hasil penelitian di atas, terlihat bahwa pengetahuan seseorang akan mempengaruhi perilaku seseorang untuk melakukan pemeriksaan kehamilan yang dilakukan bidan. Upaya yang dilakukan untuk meningkatkan perilaku bidan pada ibu hamil saat pemeriksaan kehamilan sangat diperlukan. Dikarenakan pemeriksaan kehamilan yang dilakukan oleh bidan berguna untuk memantau perkembangan kehamilan dan kondisi janin, sehingga apabila ditemukan adanya kelainan ataupun komplikasi dalam kehamilan bisa segera ditangani. Dengan begitu kualitas kesehatan ibu dan bayi akan semakin meningkat dan angka kematian ibu dan bayi dapat ditekan seminimal mungkin.

3. Mengidentifikasi pengetahuan ibu hamil tentang pemeriksaan ANC

Berdasarkan hasil penelitian tingkat pengetahuan ibu hamil tentang pemeriksaan kehamilan di wilayah kerja Puskesmas Kuripan, yang masuk pada kategori pengetahuan baik yaitu sebesar 26 orang (87\%), cukup sebanyak 4 orang $(13 \%)$.

Hasil penelitian ini juga sesuai dengan teori yang dikemukakan oleh Notoatmojo (2007), pengetahuan sangat erat kaitannya dengan pendidikan tinggi, maka orang tersebut akan semakin luas pula pengetahuannya. Namun perlu ditekankan bahwa seseorang yang berpendidikan rendah tidak mutlak berarti berpengetahuan rendah juga. Peningkatan pengetahuan tidak mutlak hanya bisa diperoleh pada jenjang pendidikan formal, akan tetapi juga dapat diperolah pada pendidikan non-formal. ${ }^{13}$ Pengetahuan menjadi landasan penting untuk menentukan suatu tindakan. Pengetahuan, sikap dan perilaku seseorang akan kesehatan merupakan 7 factor yang menentukan dalam mengambil suatu keputusan. Semakin tinggi tingkat pengetahuan seseorang semakin baik pula seseorang mampu bertindak dan mengambil keputusan yang terbaik baginya. ${ }^{?}$

Hasil penelitian ini sejalan dengan hasil penelitian mengenai gambaran tingkat pengetahuan ibu hamil dalam pemeriksaan antenatal care di wilayah kerja Puskesmas Jambon, kabupaten Ponorogo, di dapat hasil bahwa 53 (66\%) ibu hamil memiliki pengetahuan baik dan 27 (34\%) ibu hamil memilikii pengetahuan yang kurang. ${ }^{13}$

Hasil penelitian didapat ibu hamil yang memilikii pengetahuan baik dapat dipengaruhi oleh pendidikan yang dimiliki ibu hamil karena terdapat $47 \%$ ibu hamil berpendidikan menengah dan $10 \%$ berpendidikan tinggi.

Selain itu ibu hamil yang memiliki pengetahuan cukup sebanyak $13 \%$, dapat dipengaruhi oleh pendidikan ibu hamil yang berpendidikan dasar sebanyak $43 \%$. Upaya yang dilakukan untuk meningkatkan pengetahuan ibu hamil yaitu sangat 
diperlukan peran petugas kesehatan puskesmas untuk memberikan informasi melalui konseling mengenai pemeriksaan kehamilan. Sehingga dengan pengetahuan yang dimiliki, ibu dapat mengetahui mengenai pentingnya pemeriksaan kehamilan untuk kesehatan ibu dan bayinya, selain itu peran petugas kesehatan juga penting dalam melakukan penyuluhan secara rutin baik di puskesmas maupun posyandu pada ibu hamil atau masyarakat. ${ }^{14}$

4. Menganalisis pengaruh sikap dan perilaku bidan terhadap pengetahuan ibu hamil saat Pelaksanaan ANC

Berdasarkan hasil pengolahan data maka dapat dinyatakan bahwa, estimasi binary logistic regression memiliki tingkat signifikan sebesar 0.00 , artinya bahwa variabel sikap dan perilaku bidan berpengaruh terhadap pengetahuan ibu hamil saat pemeriksaan ANC.

Berdasarkan hasil penelitian sikap dan perilaku bidan terhadap pengetahuan ibu hamil saat pemeriksaan ANC, terlihat bahwa sikap dan perilaku seseorang akan mempengaruhi pengetahuan orang tersebut. Sikap dan perilaku bidan mempengaruhi dikarenakan sikap dan perilaku bidan menurut ibu hamil bermacam-macam dalam menyikapinya. $^{11}$

Berdasarkan penelitian oleh Komariyah tahun 2018 di mojokorto Kediri tentang hubungan pengetahuan, sikap dan perilaku ibu hamil tentang pemeriksaan kehamiilan dengan kunjungan pemeriksan kehamilan, didapatkan hasil adanya hubungan pengetahuan dengan kunjungan pemeriksaan kehamilan. ${ }^{18}$

Dengan sikap dan perilaku bidan yang baik diharapkan pengetahuan ibu hamil akan pemeriksaan ANC menjadi baik juga. Untuk mempertahankan pengetahuan ibu hamil, sebagai tenaga kesehatan terutama bidan perlu meningkatkan pengetahuan ibu hamil dengan konseling, penyuluhan atau dengan program-program yang lain, misalnya dengan dibentuknya kelas ibu hamil pada masing-masing posyandu sehingga pengetahuan yang di dapat tidak hanya tentang kehamilan tapi lebih menyeluruh sampai kontrasepsi. Dengan demikian diharapkan pengetahuan ibu hamil bertambah.

\section{Kesimpulan}

Berdasarkan hasil penelitian tentang pengaruh sikap dan perilaku bidan terhadap pengetahuan ibu hamil saat pemeriksaan ANC. di wilayah kerja Puskesmas Kuripan tahun 2019. Ada perngaruh sikap dan perilaku bidan terhadap pengetahuan ibu hamil saat pemeriksaan ANC $(\mathrm{p}=0,000<0,05)$ di wilayah kerja Puskesmas Kuripan tahun 2019

\section{Daftar Pustaka}

1. Arikunto, S. (2013). Prosedur Penelitian: Suatu Pendekatan Praktik. Jakarta: Rineka Cipta.

2. Arikunto, S. (2009). Manajemenn Penelitian. Jakarta: Rineka Cipta.

3. Dinas Kesehatan Provinsi NTB. 2017. Profil Kesehatan NTB 2017. Mataram: 
Dinas Kesehatan Provinsi NTB

4. Dinas Kesehatan Kabupaten Lombok Barat. 2016. Profil Kesehatan Kabupaten Lombok Barat 2017. Mataram: Dinas Kesehatan Provinsi NTB

5. Dedes Fitria. 2016. Hubungan kinerja bidan dengan kunjungan pemeriksaan kehamilan bidan praktik mandiri di Kabupaten Bogor. Di akses pada tanggal 11 Januari 2019

6. Janiwarty, Bethsaida \& Pieter, H.Z., 2013. Pendidikan Psikologi untuk Bidansuatu Teori dan Terapannya. Yogyakarta: Andi Offset

7. Komariah Siti, 2008. Hubungan pengetahuan, sikap, dan perilaku ibu hamil tentang pemeriksaan kehamilan dengan junjungan pemeriksaan kehamilan di wilayah kerja Puskesmas Sukorame Mojokerto Kediri. Di akses pada tanggal 11 januari 2019

8. Marmi \& Margiyati. 2013. Konsep Kebidanan untuk Mahasiswa Akademi Kebidanan. Yogyakarta: Pustaka Pelajar

9. Marmi. 2014. Etika profesi Bidan. Yogyakarta: Pustaka Pelajar

10. Marmi. 2011. Asuhan Kebidanan Pada Masa Antenatal. Yogyakarta: Pustaka Pelajar.

11. Marpua. 2017. Hubungan Pengetahuan Dan Sikap Bidan Dalam Pelaksanaan Standar Antenatal Care 10 Tdi Wilayah Kerja Puskesmas Lambuyakabupaten Konawetahun 2017. Di akses pada tanggal 6 april 2019

12. Menteri Kesehatan Republik Indonesia, 2017. Peraturan menteri kesehatan republik indonesia nomor 28 tahun 2017 tentang izin dan penyelenggaraan praktik bidan. Di akses pada tanggal 25 januari 2019

13. Notoatmodjo, 2012. Ilmu Perilaku kesehatan. Jakarta : Renika Cipta

14. Purwantini, 2012. gambaran tingkat pengetahuan ibu hamil dalam pemeriksaan antenatal care di wilayah kerja Puskesmas Jambon, kabupaten Ponorogo.

15. Rahayu Siti \& Indiatri Resqi, 2017. Pengaruh kualitas pemeriksaan kehamilan oleh bidan terhadap kepuasan ibu hamil di uskesmas Brangsong I kabupaten Kendal. Di akses pada tanggal 11 Januari 2019

16. Setyaningsih, Dewi Novita. 2011. Gambaran Perilaku Bidan Dalam Menerapkan Standar Pelayanan Kebidanan Pada Pemeriksan

Pemantauan Antenatal Di BPS Wilayah Desa Ambartawang Magelang Tahun 2011. Di akses pada tanggal 6 april 2019

17. Sugiyono. (2010). Statistika untuk Penelitian. Bandung: Penerbit Alfabeta

18. Sugiyono. (2014). Metode Penelitian Kuantitatif, kualitatif, dan R\&D. Bandung: Penerbit Alfabeta.

19. Winarni. 2014. Kepuasan Ibu Hamil Terhadap Pelayanan ANC oleh Bidan Di Wilayah Kerja Puskesmas Ngoresan. Di akses pada tanggal 11 Januari 2019. 